\title{
A Model for Estimating Passenger-Car Carbon Emissions that Accounts for Uphill, Downhill and Flat Roads
}

\author{
Jinliang Xu, Yaping Dong *(D) and Menghua Yan $(\mathbb{D}$ \\ School of Highway, Chang'an University, Xi'an 710064, China; xujinliang@chd.edu.cn (J.X.); \\ menghuayan@chd.edu.cn (M.Y.) \\ * Correspondence: yapingdong@chd.edu.cn
}

Received: 16 January 2020; Accepted: 4 March 2020; Published: 6 March 2020

check for updates

\begin{abstract}
The geometric longitudinal slope line of a given road significantly effects the carbon emissions of vehicles traversing it. This study was conducted to explore the carbon emission rules of passenger cars on various highway slopes. The law of conservation of mechanical energy, the first law of thermodynamics and the vehicle longitudinal dynamics theory were utilized to determine the influence of slope design indicators on fuel consumption. The energy conversion, fuel consumption, and carbon emission models of passenger cars on a flat straight road, uphill road, and downhill road sections were derived accordingly. Two types of passenger cars were selected for analysis. A field test was carried out to verify the proposed model where the vehicle maintained a cruise speed on flat straight road, uphill road and downhill road with equal gradient and mileage, and continuous longitudinal slope to gather fuel consumption data. The proposed model showed strong accuracy and a maximum error of $9.97 \%$. The main factor affecting the vehicle's carbon emissions on the continuous longitudinal slope was found to be the average gradient. For a round-trip longitudinal slope with a small gradient, the main factor affecting the vehicle's carbon emissions is speed: higher speed results in higher carbon emissions. The results of this study are likely to provide the data for support and a workable reference for the low-carbon highway design and operation.
\end{abstract}

Keywords: carbon emissions; prediction model; uphill; downhill; continuous longitudinal slope; gradient; low carbon design; two-way traffic; highway

\section{Introduction}

Carbon emissions control is an environmental issue of widespread international concern. The longitudinal slope design indicator has crucial effect on the carbon emitted by various vehicles. When driving conditions such as speed, vehicle type, vehicle load, road pavement conditions, and road environment remain unchanged, vehicles consume fluctuating quantities of fuel when moving uphill versus as they perform additional work to overcome height differences on uphill roads $[1,2]$. The relationship between longitudinal slope design indicators and vehicle carbon emissions has a great deal of practical significance and has been explored by many researchers. Researchers have found that targeting longitudinal slope roads may be an effective approach to reducing fuel consumption and carbon emissions [2,3]. Quantifying the carbon emissions of vehicles in vertical profile and exploring the influence of design indicators on carbon emissions are important for the design of low-carbon vertical profiles. Governments and road operation management agencies may be able to directly control the total carbon emissions of two-way traffic flows on highways constituted by integral subgrades. The influence of design indexes on the carbon emissions of vehicles traversing flat, uphill, and downhill road sections must first be determined to support such control measures. Previous studies have also 
shown that energy-saving and emission-reduction effects can be achieved by controlling longitudinal slope design indexes in particular [1-3].

Fuel economy refers to the ability of a vehicle to operate economically, i.e., consuming as little fuel as possible, while ensuring dynamic performance [4,5]. Fuel consumption in this case corresponds to minimum carbon emissions levels [3]. Certain scholars dedicated to this subject have focused on improving energy efficiency and reducing greenhouse gas emissions in transportation systems through research on new energy vehicle [6,7] and controlling vehicle speeds [8-10]. Dreier et al. [6] analyzed the influence of passenger load, driving cycle, fuel price and four different types of buses on the cost of transport service on a rapid transit route in Curitiba, Brazil. The technology-economic optimization model was used to identify an alternative to the conventional bi-articulated bus fleet currently in operation, with the goal of minimizing weekly transportation service costs. Dreier et al. [7] also conducted a well-to-wheel comparative analysis of fossil energy use and greenhouse gas emissions for conventional, hybrid-electric and plug-in hybrid-electric city buses in the Curitiba bus rapid transit system; they found that advanced powertrains and larger passenger capacity utilization can contribute to the system's sustainability. According to numerous previous studies [8-10], a vehicle consumes less fuel when traveling at a constant speed than at a fluctuating speed. Chang and Morlok [9] suggested that the optimal speed profile for fuel consumption of a motor vehicle, under various roadway characteristics, is achieved at cruising speed.

The design indexes of the longitudinal slope affect the driving power of individual vehicles [3]. Vehicle power, in turn, is closely related to fuel consumption and carbon emissions [2,3]. Various micro carbon emission models, including the Comprehensive Modal Emissions Model (CMEM) [11-13] and Motor Vehicle Emission Simulator (MOVES) [14] reflect the real-time operating conditions of vehicles. Barth and Scora et al. [11,12] conducted laboratory dynamometer tests on 343 light-duty trucks to test vehicle speed, fuel consumption, and exhaust emissions data under various operating conditions. The regression estimation method was adopted to construct the CMEM [12,13] of a light truck with factors such as road gradient, instantaneous speed, engine transmission coefficient, vehicle frontal area, and road friction coefficient. This study was limited by the fact that the laboratory dynamometer test does not fully reflect real-world driving conditions. There are also differences in vehicle performance and fuel characteristics in various regions which limit the practical application of the CMEM $[13,15,16]$.

The US Environmental Protection Agency adopted the Portable Emission Measurement System (PEMS) to collect vehicle speed and exhaust emissions data. Vehicle specific power and instantaneous speed were then used to characterize actual vehicle operating conditions. The Motor Vehicle Exhaust Emission Model (MOVES) [14] was developed based on measured vehicle operating conditions, road type, gradient, temperature, fuel consumption, and exhaust emissions data. Ko et al. [17] used a dynamics non-uniform velocity model established by Lan and Menendez [18] to simulate the instantaneous speed of a $120 \mathrm{~kg} / \mathrm{kW}$ truck on a longitudinal slope, then used MOVES to predict the carbon emissions of the truck as it traveled uphill. The gradient was shown to have the greatest impact on the truck's carbon emissions among all indicators observed. When the mileage was $3000 \mathrm{~m}$, the carbon emissions of the vehicle on the $9 \%$ gradient were about four-fold greater than on a straight, flat road. However, the influence of driving behavior, such as acceleration and deceleration, was not ruled out-thus, no substantive suggestions regarding the gradient value in the low-carbon design of the longitudinal slope have been put forward to data. Moreover, the default values of related parameters in the model apply to local US conditions, which differ from vehicle performance, fuel characteristics, temperature, altitude, and other notable test factors in China $[13,15,16]$. This model cannot be directly applied to estimate the fuel consumption and carbon emissions of Chinese vehicles.

Vehicle fuel consumption models based on vehicle dynamics theory are relatively authoritative. Scholars have investigated the fuel consumption and driving power of vehicles under certain driving forces using vehicle dynamics theory [8-10], including a few studies on the influence of highway longitudinal gradients on fuel consumption. Barth and Scora et al. [11,12] analyzed the driving power of a vehicle on uphill sections with factors such as engine transmission coefficient, instantaneous 
speed, road gradient, vehicle frontal area, and road friction coefficient using vehicle dynamics theory; they found a close relationship between driving force and fuel consumption. Different driving forces interact with different operating conditions. The CMEM models of light-duty trucks was developed based on measured operating conditions data from laboratory dynamometer tests. Kang [8] used the tractive effort model of a vehicle on the longitudinal slope road proposed by Chang [9] to build a new model of the relationship between fuel consumption and tractive effort with fuel consumption rate as a conversion factor. Fuel consumption rate is affected by factors such as vehicle load, engine type, and environmental conditions. Fuel consumed is approximately proportional to total propulsive work performed by the prime movers. Chang [9] indicated that vehicle dynamic conditions on flat road, uphill road, and downhill road sections notably differ, and divided the vehicle dynamic load on the downhill section into two cases: one where the gravity potential energy completely offsets the air resistance and the rolling resistance, and one where the gravity potential energy is greater than the road resistance. Various balance gradients applicable to the first case have been proposed for different vehicle loads, but mechanical resistance has not yet been considered and only the fuel consumption in the first case was assessed. The fuel consumption rate in the models was also idealized and was considered a constant. There has been no model verification based on field test data [8,9]. It is worth noting that the models indicate that vehicle fuel consumption is approximately proportional to the total propulsive work of the vehicle, and that the slope affects the total driving power to a certain extent.

Kanok and Barth [1] conducted a fuel consumption field test on uphill, downhill, and flat road sections with a maximum gradient of $6 \%$ in a passenger car maintaining a cruise speed of $96 \mathrm{~km} / \mathrm{h}$. The results showed that the vehicle's fuel consumption was greatest on the uphill section, followed by the flat road and finally the downhill section. The fuel economy on a plain route was also found to be better than on a mountainous route. The relationship between the fuel consumption measured and the road grade appeared to be linear within the grade range $-2 \%$ to $2 \%$, which implies that there would be no difference in fuel consumption among round-trip mountainous routes within such a range versus flat route. The fuel consumption of the vehicle on the flat road was $18 \%$ lower than the fuel consumption on the combination of uphill and downhill roads with a gradient of $6 \%$. Due to lack of theoretical basis and insufficient experimental data for each road grade, this study did not reveal the extent to which the gradient affects vehicle fuel consumption. The gradient was not clearly defined when the fuel consumption was similar on the uphill-downhill combination and flat road. The extant research on vehicle fuel consumption and carbon emissions centers on driving behavior [11-14,17] and vehicle power loads [8-10]. The road gradient is known to more significantly influence vehicle carbon emission rate than the factors of rolling resistance, acceleration rate, frontal area, temperature [10]. Existing micro carbon emission models, such as CEME and MOVES, were established on large quantities of measured or simulated data [11-14]; arguably, the theoretical basis of these models is insufficient. The default parameters in these micro models are also inconsistent with China's specific conditions $[15,16]$ and cannot be directly applied to the estimation of vehicle fuel consumption or carbon emissions in China. Scholars have yet to clarify the impact of gradient on vehicle fuel consumption. It is also not yet empirically known whether vehicle fuel consumption is equivalent on flat roads versus uphill-downhill combination roads. Considering that traffic is usually two-way, it is necessary to explore this issue. It is impossible to secure the scientific mathematical models and theoretical guidance necessary for decision-making regarding innovative, low-carbon highway longitudinal slope designs without this information. The mathematical fuel consumption models established using vehicle dynamics theory are relatively authoritative, but they do not consider the mechanical resistance and fuel consumption rates of different fuel types [8,9]. It is worth considering that the research on vehicle fuel consumption and driving power under certain driving force conditions based on vehicle dynamics theory [8-10] does provide a theoretical basis for establishing a mathematical model of propulsive energy, fuel consumption, and carbon emissions for vehicles on longitudinal slopes in China. Passenger cars have good power performance and can generally travel uphill at the average speed of all vehicles on the road $[19,20]$. The fuel consumption of a motor vehicle is approximately minimized by operating at 
cruising speed [8-10]. In this study, the speed of a passenger car on the longitudinal slope road was assumed to be uniform in conformity with real-world vehicle operation conditions, and as is conducive to further research on the energy-saving and low-carbon highway longitudinal slope design.

The present study was conducted to establish a quantified model of carbon emissions of passenger cars on uphill, downhill, and flat roads. The carbon emissions rules of passenger cars on longitudinal slope sections were investigated to secure low-carbon and fuel-economy-related longitudinal slope design indicators. The energy conversion of a vehicle in overcoming height differences was determined based on vehicle longitudinal dynamics theory, the law of conservation of mechanical energy, and the first law of thermodynamics. Universally applicable fuel consumption and carbon emission models for passenger cars on highway longitudinal slopes were established to explore the corresponding carbon emission rules. A theoretical model was evaluated using field test data. A combination of theoretical and empirical research methods was deployed to ensure reliable conclusions.

The remainder of this paper is organized as follows. Section 2 discusses the law of conservation of mechanical energy and the first law of thermodynamics as-utilized to assess the energy conversion of a vehicle on a longitudinal slope road. The conversion of energy, fuel consumption, and carbon emissions proposed by the Intergovernmental Panel on Climate Change (IPCC) is used to account for the carbon emissions of the passenger car as it traverses a longitudinal slope. The importance of the balance gradient is highlighted in this section as well. In Section 3, the accuracy of the passenger car's carbon emission model is evaluated by field tests conducted on flat, uphill, downhill, symmetrical slope combination, and continuous longitudinal slop road sections. The carbon emission rule of vehicles on the longitudinal highway slope is confirmed by test results. Section 4 summarizes the key findings alongside a discussion on the limitations of this work.

\section{Carbon Emission Model}

In this section, the law of conservation of mechanical energy, the first law of thermodynamics, the vehicle longitudinal dynamics theory, and the accounting method proposed by IPCC for energy, fuel consumption, and carbon emissions are used to establish the carbon emission model of passenger car on uphill, downhill, and flat sections. Meanwhile, the proposed carbon emission model reveals the carbon emission rules of vehicles on the longitudinal section.

For the proposed energy conversion, fuel consumption, and carbon emission models, the following are assumed:

a. The driver of the passenger car maintains a uniform speed. The American Association of State Highway and Transportation Officials (AASHTO) indicates that the passenger car is relatively unaffected by the road gradient when driving on a longitudinal slope due to its acceptable power performance. Almost all passenger cars can traverse $4 \%$ to $5 \%$ steep slopes at a uniform speed without deceleration [19]. The Japan Road Association states that the general gradient value ensures that passenger cars can travel uphill at a uniform speed; this speed is the average speed of all vehicles on the road [20]. The Chinese "Technical Standard of Highway Engineering" indicates that passenger vehicles generally run at a constant and relatively high speed on highways in a free flow pattern, do not interfere with each other, and do not significantly fluctuate in speed [21]. The assumption that the passenger vehicle maintains a uniform speed in traversing a longitudinal slope is consistent with real-world driving conditions in free flow patterns. Cruising can prevent the interference from speed fluctuations on carbon emissions, which is conducive to research on fuel economy and carbon reduction in highway longitudinal slope design;

b. All frictional heat is absorbed by the brake drum when braking. The effects of other parts of the brake chamber during heat generation and heat dissipation are generally negligible [4,22], which is conducive to the establishment of an energy conversion model for vehicles on longitudinal slope sections. The positive work of gravity converts the gravitational potential energy into the kinetic energy of the vehicle, during grade descent. The kinetic energy is controlled by the brake operation, while the friction at the drum interface simultaneously generates heat [22]. 


\subsection{Energy Conversion Model}

As the vehicle runs, chemical energy in its fuel is converted into mechanical energy through a combustion process in the engine. Mechanical energy is converted into kinetic energy via the vehicle's transmission and tire systems. There is energy loss in every link, mainly in regards to engine combustion efficiency, transmission system efficiency, tire rolling resistance, aerodynamic resistance, and brake friction $[4,5,23]$. The vehicle dynamic conditions on a flat road, uphill road, and downhill road sections are different [3-5]. Vehicle dynamics theory was used in this study to analyze the force of vehicles on various road sections and to establish vehicle energy conversion models accordingly. The influence of the gradient on vehicle carbon emissions was observed by comparing the vehicle energy conversion model of the flat road and a combination of symmetrical slope road sections.

\subsubsection{Flat Road}

Aerodynamic resistance and rolling resistance act on the vehicle as the vehicle travels across a flat, straight road. The effective tractive effort of the vehicle is related to its engine power, travel speed, and transmission efficiency $[4,5,24]$, as follows:

$$
\mathrm{F}=\mathrm{F}_{\mathrm{i}} \mathrm{n}_{\mathrm{tf}}
$$

where $F_{i}$ is the indicated tractive effort $(N)$, which is equal to the total resistance of the vehicle $[4,5]$; $F$ is the effective tractive effort. The transmission efficiency $n_{t f}$ is reflected in the mechanical losses of the various transmission system components (transmission, transmission shaft, differential, and drive shaft). As the vehicle travels at a uniform speed, the engine speed is in an optimal working state and the transmission efficiency remains constant. When predicting vehicle power performance, the transmission efficiency of the current common passenger car is usually estimated to be approximately $85 \%[4,24]$.

The vehicle is also subject to aerodynamic resistance during driving. The aerodynamic resistance is proportional to the dynamic pressure of the relative speed of the air $[5,25]$, as follows:

$$
\mathrm{F}_{\mathrm{a}}=\frac{1}{2} \mathrm{AC}_{\mathrm{D}} \rho \mathrm{V}^{2},
$$

where $A$ is the vehicle frontal area $\left(\mathrm{m}^{2}\right)$, i.e., the area of the car from the front to the rear [5]. $\rho$ is the air density, generally $1.2258 \mathrm{~N} \cdot \mathrm{s}^{2} / \mathrm{m}^{4}$. The aerodynamic resistance coefficient $C_{D}$ is related to the shape of the vehicle. The air resistance coefficients of various shapes of vehicles can be obtained from related documents on vehicle characteristics $[5,25]$. $\mathrm{V}$ is the relative speed of the vehicle and air considering the angle between the wind and the driving direction $(\mathrm{m} / \mathrm{s})$.

On the highway longitudinal slope, the gradient is very small. It can be assumed that the length of the slope is approximately equal to the horizontal distance. The work done by aerodynamic resistance is as follows:

$$
\mathrm{W}_{\mathrm{a}}=\mathrm{F}_{\mathrm{a}} \mathrm{S},
$$

Rolling resistance is related to tire type, road type, and speed [22,24]. It can be approximated as follows:

$$
\mathrm{F}_{\mathrm{r}}=\mathrm{mgC}_{\mathrm{r}}\left(\mathrm{C}_{2} \mathrm{v}+\mathrm{C}_{3}\right) / 1000,
$$

where $v$ is the vehicle speed $(\mathrm{km} / \mathrm{h})$. The rolling coefficient $C_{\mathrm{r}}$ is related to the pavement type and condition, typical values are available in the literature of Rakha [24]. Rolling resistance constants $C_{2}$ and $C_{3}$ are related to tire type and can be assigned values as determined empirically. For the mixed tires commonly used in passenger cars, $C_{2}=5.3$ and $C_{3}=0.044$ [22].

The work done by rolling resistance is:

$$
\mathrm{W}_{\mathrm{r}}=\mathrm{F}_{\mathrm{r}} \mathrm{S}
$$




\subsubsection{Uphill}

The tractive effort of vehicles is affected by driving resistance on uphill roads. The driving resistance includes slope resistance, rolling resistance, and aerodynamic resistance. The slope resistance is the component of the vehicle's weight parallel to the road surface [4]. The vehicle's gravity performs negative work parallel to the road surface, as indicated in Equations (6) and (7).

$$
\begin{aligned}
& \mathrm{F}_{\mathrm{g}}=\mathrm{mgi}, \\
& \mathrm{W}_{\mathrm{g}}=\mathrm{F}_{\mathrm{g}} \mathrm{S},
\end{aligned}
$$

where $\mathrm{i}$ is the road gradient $(\%)$.

\subsubsection{Downhill}

A portion of the gravity parallel to the road surface plays a positive role as the vehicle travels downhill. Rolling resistance, aerodynamic resistance, and braking force do negative work. It is worth noting that when the vehicle travels uphill along a straight trajectory, the torque direction of the engine is transmitted from the engine to the wheels. When the vehicle goes downhill, conversely, gravity increases the kinetic energy of the vehicle. If the accelerator pedal is not pressed and the gear is still in the gear position, the engine is in the reversed state and the torque direction is opposing. The reverse tractive force of the transmission system generates resistance to the vehicle $[4,5]$. A greater gradient produces greater gravitational potential energy. When the gradient is large, the vehicle will accelerate even if the accelerator is not pressed and the vehicle can slide downhill in the gear position. A portion of the gravitational potential energy offsets the energy lost by the transmission system [4]. Chang [9] analyzed a case in which the vehicle requires no braking to maintain a constant speed on the downgrade. The inherent forces (rolling resistance, wind resistance) and gradient force cancel one another in this case and no propulsive work is required. However, the transmission resistance was not considered.

There are three cases of driving behavior which emerge as the vehicle maintains a cruise speed across various gradients.

a. In Case I, when the accelerator is not pressed, the vehicle can slide downhill in the gear position at a cruise speed. The gravitational potential energy can offset the negative worked by rolling resistance, wind resistance, and reverse tractive force $[4,5,9]$. In this case, the vehicle meets the following energy relationship:

$$
E_{g}=W_{r}+W_{a}+W_{t^{\prime}}
$$

where, $\mathrm{W}_{\mathrm{t}}{ }^{\prime}$ is the indicated the energy loss caused by reverse tractive force $(\mathrm{J})$.

When the vehicle does not slide downhill at the gear position, the reverse traction does not work and $W_{t}{ }^{\prime}=0$ [4]. The balance gradient corresponding to the cruise speed can be calculated according to the specific driving road conditions of the vehicle.

b. In Case II, when the work of driving resistance and aerodynamic resistance is greater than the gravitational potential energy, the driver must step on the accelerator to provide additional energy and ensure that the vehicle maintains the cruise speed. The energy relationship is as follows:

$$
\mathrm{W}+\mathrm{E}_{\mathrm{g}}=\mathrm{W}_{\mathrm{r}}+\mathrm{W}_{\mathrm{a}}
$$

c. In Case III, when the work of driving resistance and aerodynamic resistance is less than the gravitational potential energy, the remaining gravitational potential energy is converted into kinetic energy which provides a certain increase in the vehicle's speed. In order to maintain the cruise speed at this point, the driver needs to step on the brake to ensure that the kinetic energy not increased. The braking force produces brake drum heat $\mathrm{Q}_{\mathrm{h}}$ [22]. According to the first law of thermodynamics, the energy relationship in this case is as follows: 


$$
\mathrm{E}_{\mathrm{g}}=\mathrm{W}_{\mathrm{r}}+\mathrm{W}_{\mathrm{a}}+\mathrm{W}_{\mathrm{t}}{ }^{\prime}+\mathrm{Q}_{\mathrm{h}}
$$

The energy loss value on the downhill road is theoretically equal to the difference between the energy of gravity potential and the energy consumed by driving resistance. Compared to the propulsive energy traveling uphill with the balance gradient, the increase in propulsive energy when traveling uphill (which overcomes the increased elevation difference) is equal to the energy loss of vehicle when traveling downhill.

\subsubsection{Symmetrical Slope Combination Road}

The energy of a combination of symmetrical uphill-downhill and flat roads were compared to explore the impact of the road gradient on vehicle carbon emissions The uphill-downhill combination is required to be symmetrical in gradient and slope length, and the slope length is equal to the flat road length. The energy provided by the effective tractive effort of the vehicle on the flat, uphill, and downhill road sections in this case are $\mathrm{W}_{1}, \mathrm{~W}_{2}, \mathrm{~W}_{3}$, respectively. The propulsive energy formulations of the vehicle on flat and uphill sections are expressed as follows:

$$
\begin{gathered}
\mathrm{W}_{1}=2\left(\mathrm{~W}_{\mathrm{r}}+\mathrm{W}_{\mathrm{a}}\right), \\
\mathrm{W}_{2}=\mathrm{E}_{\mathrm{g}}+\mathrm{W}_{\mathrm{r}}+\mathrm{W}_{\mathrm{a}},
\end{gathered}
$$

The vehicle's energy conversion formulations on downhill road sections in Case I, Case II, Case III are reflected in Equations (13) and (14), Equation (15), Equations (16) and (17), respectively.

$$
\begin{gathered}
\mathrm{E}_{\mathrm{g}}=\mathrm{W}_{\mathrm{r}}+\mathrm{W}_{\mathrm{a}}+\mathrm{W}_{\mathrm{t}^{\prime},} \\
\mathrm{W}_{3}=0, \\
\mathrm{~W}_{2}+\mathrm{E}_{\mathrm{g}}=\mathrm{W}_{\mathrm{r}}+\mathrm{W}_{\mathrm{a}}, \\
\mathrm{E}_{\mathrm{g}}=\mathrm{W}_{\mathrm{r}}+\mathrm{W}_{\mathrm{a}}+\mathrm{W}_{\mathrm{t}}{ }^{\prime}+\mathrm{Q}_{\mathrm{h}}, \\
\mathrm{W}_{3}=0,
\end{gathered}
$$

The respective energy relationships of the vehicle on the three types of symmetrical slope combination roads are as follows.

$$
\begin{gathered}
\mathrm{W}_{2}+\mathrm{W}_{\mathrm{t}}=2\left(\mathrm{~W}_{\mathrm{r}}+\mathrm{W}_{\mathrm{a}}\right)+\mathrm{W}_{\mathrm{t}^{\prime},} \\
\mathrm{W}_{2}+\mathrm{W}_{3}=2\left(\mathrm{~W}_{\mathrm{r}}+\mathrm{W}_{\mathrm{a}}\right), \\
\mathrm{W}_{2}+\mathrm{W}_{\mathrm{t}}=2\left(\mathrm{~W}_{\mathrm{r}}+\mathrm{W}_{\mathrm{a}}\right)+\mathrm{W}_{\mathrm{t}}{ }^{\prime}+\mathrm{Q}_{\mathrm{h}},
\end{gathered}
$$

Equations (11) and (19) show that the vehicle carbon emissions of the longitudinal slope combination road II and the flat road are equivalent. The difference between energy consumed by the transmission system and energy loss caused by reverse tractive force was usually ignored in derivation of vehicle longitudinal power [4]. This indicates that the carbon emissions of the symmetrical slope combination road I and the flat road are basically equivalent. The energy provided by the engine on symmetrical slope combination roads I, II and the flat road is basically equal. The difference in fuel 
consumption between the uphill section and flat road is equal to the difference in fuel consumption between the flat road and downhill section, as shown in Equations (11), (18) and (19).

In the symmetrical slope combination road III, the gradient is greater than the balance gradient. The energy loss during braking on the downhill section is equal to the difference in energy provided by the tractive effort between the uphill section and the flat road, as shown in Equations (11) and (20).

When the gradient of the longitudinal slope is not greater than the balance gradient, the vehicle emits roughly the same amount of carbon on the symmetrical slope combination road and the flat road. When the gradient of the downhill slope exceeds the balance gradient, a steeper gradient and longer grade length cause more energy to be lost by the brake. The energy loss is equal to the propulsive energy difference on the uphill and a flat road with equal mileage. Brake energy loss is offset by the excess propulsive energy on the uphill compared with the propulsive energy on the flat road with equal mileage of symmetrical slope combination roads. It is not conducive to energy-saving or emission-reduction in regard to the two-way traffic on the longitudinal slope. The balance gradient is the minimum gradient that affects vehicle's fuel consumption and carbon emissions of two-way traffic. The gradient should be avoided to be greater than the balance gradient during the low-carbon longitudinal slope design.

\subsubsection{Continuous Longitudinal Slope}

The energy of continuous longitudinal slope sections and single longitudinal slope sections were compared to explore the carbon emissions rules of passenger vehicles on the vertical profile. The propulsive energy corresponding to the continuous uphill road section can be calculated by Equations (21) and (22). The energy is equal to the propulsive energy on the slope with average gradient and equal mileage, as reflected in Equation (23).

$$
\begin{gathered}
W=\sum_{j=1}^{n}\left(F_{a}+F_{r}+F_{g}\right)_{(j)} x_{j}, \\
W=S\left(F_{a}+F_{r}\right)+\sum_{j=1}^{n} \operatorname{mgi}_{(j)} x_{j}, \\
W=S\left(F_{a}+F_{r}+m g \bar{i}\right),
\end{gathered}
$$

When the gradient of each downhill section on the continuous downhill road is not greater than the balance gradient, the propulsive energy can be calculated by Equations (24) and (25). The energy is equal to the propulsive energy on the slope with the average gradient and equal mileage as derived by Equation (26):

$$
\begin{gathered}
W=\sum_{j=1}^{n}\left(F_{a}+F_{r}-F_{g}\right)_{(j)} x_{j}, \\
W=S\left(F_{a}+F_{r}\right)-\sum_{j=1}^{n} \operatorname{mgi}_{(j)} x_{j}, \\
W=S\left(F_{a}+F_{r}-m g \bar{i}\right),
\end{gathered}
$$

where $i_{j}, x_{j}$ represent the gradient and length of each slope section, respectively. The number of single slope sections on the continuous longitudinal slope is $n ; \bar{i}$ is the average gradient (\%) of the continuous longitudinal slope. 
A quadratic parabola is usually used as a vertical curve to connect the two longitudinal slopes at the turning point of the slope sections (Equation (27)) [26]. It is necessary to consider the vertical curve section in predicting the vehicle's carbon emissions on longitudinal slopes.

$$
y=\frac{x^{2}}{2 k}+i^{\prime} x,
$$

where $\mathrm{x}$ is the lateral distance, that is, the distance from any point to the starting point of the vertical curve; $i^{\prime}$ is the gradient of any point of the vertical curve, $i^{\prime}=\frac{x}{R}+i_{1}$. At the beginning of the vertical curve, $x=0, i^{\prime}=i_{1}$. At the end of the vertical curve, $x=L, i^{\prime}=i_{1}+\frac{L}{R}=i_{2} \cdot i_{1}$ and $i_{2}$ are the gradients of the longitudinal slopes connected to the ends of the vertical curve. $L$ is the length of the vertical curve.

The vertical curve is divided into $\mathrm{n}$ longitudinal slopes each with length of $\Delta \mathrm{x}$. The fuel consumption of the vehicle in the vertical curve section is the sum of the fuel consumption of the vehicle on the longitudinal slope of different gradients corresponding to each step, as shown in Equation (28).

$$
\text { Fuel }=\sum_{j=L / n}^{\mathrm{L}} \operatorname{Fuel}\left(\Delta \mathrm{x}_{\mathrm{j}}\right),
$$

The vertical curve section can be regarded as the connection of multiple slope sections. The energy of vehicles on the vertical curve satisfies the above energy conversion relationship.

For continuous longitudinal slopes with a fixed height differences, when the gradient of each downhill section is not greater than the balance gradient, the propulsion energy on the continuous longitudinal segment is equal to the propulsive energy on the slope with average gradient and equal mileage regardless of the design index (gradient and slope length) of each slope section.

\subsection{Conversion Among Energy, Fuel Consumption, Carbon Emissions}

Fuel is the source of propulsive energy for vehicles. In recent years, China's motor vehicles have been required to meet the National Fifth-phase Motor Vehicle Pollutant Emission standards [27]. Gasoline vehicles are generally equipped with a spark ignition gasoline engine. Moreover, the characteristic of fuels supplied to gasoline vehicles must meet the National Fifth-phase Standards of Gasoline for Motor Vehicles [28]. The density of gasoline(p) type 92\#, 95\#, and 98\# is $0.725 \mathrm{~kg} / \mathrm{L}$, $0.737 \mathrm{~kg} / \mathrm{L}$, and $0.753 \mathrm{~kg} / \mathrm{L}$, respectively [29]. The average low calorific value of gasoline(A) is $44.800(\mathrm{~kJ} / \mathrm{kg})$. The calorific values of burning one liter of different density gasoline is $32480 \mathrm{~kJ} / \mathrm{L}$, $33017.6 \mathrm{~kJ} / \mathrm{L}$, and $33734.4 \mathrm{~kJ} / \mathrm{L}$ respectively. According to the first law of thermodynamics, energy is conserved when thermal energy and mechanical energy are converted. The fuel utilization rate is the proportion of fuel that provides drive energy to the total fuel, as presented in Equation (29). The fuel utilization rate of a spark ignition gasoline engine, $n_{m}$, is generally $27 \%[5,10,30]$. The remaining energy is converted into heat and then lost. The fuel consumption of gasoline of different densities in China can be calculated according to Equations (30)-(32).

$$
\begin{aligned}
\text { Fuel } & =\frac{10^{-3} \mathrm{~W}}{\mathrm{n}_{\mathrm{tf}} \mathrm{n}_{\mathrm{mPA}}}, \\
\operatorname{Fuel}_{(92 \#)} & =1.342 \times 10^{-7} \mathrm{~W}, \\
\operatorname{Fuel}_{(95 \#)} & =1.320 \times 10^{-7} \mathrm{~W}, \\
\operatorname{Fuel}_{(98 \#)} & =1.292 \times 10^{-7} \mathrm{~W},
\end{aligned}
$$

where, Fuel indicates fuel consumption (L).

The IPCC accounting method [31] was adopted here to observe the relationship between vehicle fuel consumption and carbon emissions, as shown in Equation (33). This prevented measurement error 
otherwise caused by various factors when directly detecting gas from the exhaust pipe of the test vehicle. The conclusions of this study are comparable with extant results from similar work in other countries; the universal applicability of the research results presented here is guaranteed [15,16]. Data relevant to the extant vehicle fuel characteristics in China can be found in the "National Communication on Climate Change of China" [32,33]. The potential carbon emission factor (C) is $18.9(\mathrm{t} / \mathrm{TJ})$, the carbon conversion factor(K) is $44 / 12$, and the carbon oxidation rate (B) is $98 \%$. It can be obtained that the carbon emission from burning one liter of gasoline type $92 \#, 95 \#$, and $98 \#$ is $2.206 \mathrm{~kg} / \mathrm{L}, 2.242 \mathrm{~kg} / \mathrm{L}$, and $2.291 \mathrm{~kg} / \mathrm{L}$, respectively, as shown in Equations (34)-(36).

$$
\begin{gathered}
\mathrm{CO}_{2}=\mathrm{ACBKp} \times \text { Fuel } \times 10^{-3}, \\
\mathrm{CO}_{2(92 \#)}=2.206 \times \text { Fuel, } \\
\mathrm{CO}_{2(95 \#)}=2.242 \times \text { Fuel, } \\
\mathrm{CO}_{2(98 \#)}=2.291 \times \text { Fuel, }
\end{gathered}
$$

where, $\mathrm{CO}_{2}$ represents carbon emissions $(\mathrm{kg})$.

The vehicle engine burns a certain amount of fuel to provide the effective tractive effort to overcome aerodynamic resistance and rolling resistance while traversing a flat road [5,22]. The effective tractive effort of the vehicle on the uphill section must overcome slope resistance, aerodynamic resistance, and rolling resistance $[4,5]$. Greater tractive effort results in greater the fuel consumption and more carbon emissions [3]. On the downhill section, when the vehicle's gravitational potential energy is equal to or greater than the energy consumed by aerodynamic resistance and rolling resistance, the vehicle does not need to provide any additional tractive effort and there is no fuel consumed or carbon emitted. When the aerodynamic resistance and rolling resistance consumes more energy than the gravitational potential energy, the vehicle must provide tractive effort to maintain the cruise speed and consumes a certain amount of fuel while emitting a certain amount of carbon $[4,5,9]$. There is constant idle fuel when the vehicle is not under neutral operation conditions [3].

Considering the heat generation of different fuel types, transmission efficiency and fuel utilization rate, the fuel consumption of different fuel types can be determined as the engine provides a certain driving energy, as indicated in Equations (37)-(39). When fuels of different densities produce equal driving energy, they correspond to uniform quantities of carbon emissions, as demonstrated in Equations (40)-(42).

$$
\begin{gathered}
\text { Fuel }_{(92 \#)}=1.341 \times 10^{-7} \mathrm{~W}+\mathrm{Qt}, \\
\text { Fuel }_{(95 \#)}=1.320 \times 10^{-7} \mathrm{~W}+\mathrm{Qt}, \\
\text { Fuel }_{(98 \#)}=1.292 \times 10^{-7} \mathrm{~W}+\mathrm{Qt}, \\
\mathrm{CO}_{2(92 \#)}=2.959 \times 10^{-7} \mathrm{~W}+2.206 \times \mathrm{Qt}, \\
\mathrm{CO}_{2(95 \#)}=2.959 \times 10^{-7} \mathrm{~W}+2.242 \times \mathrm{Qt}, \\
\mathrm{CO}_{2(98 \#)}=2.959 \times 10^{-7} \mathrm{~W}+2.291 \times \mathrm{Qt},
\end{gathered}
$$

where, $\mathrm{Q}$ is the constant idle fuel rate $(\mathrm{L} / \mathrm{h}) . \mathrm{t}$ is the travel time $(\mathrm{h})$.

\section{Model Verification}

Field test can directly reflect the vehicle's carbon emissions under actual road conditions. A field test was carried out in this study to validate the proposed theoretical carbon emission model. The above carbon emission rules for longitudinal slope sections were also validated against real-world data from the field test. 


\subsection{Field Test}

Typical flat road, single slope, and continuous longitudinal slope road sections were selected to gather vehicle speed and fuel consumption data. The IPCC carbon emission conversion methodology was adopted to convert the fuel consumption into carbon emissions. There are different balance gradients for vehicles with different loads [9]. The vehicle to slid downhill in the gear position and the accelerator was not pressed in the balance gradient test to measure the speed at which the vehicle can cruise. In the fuel consumption test, the driver was required to enable the cruise control function of the test vehicle to maintain a constant speed on the test roads. These tests formally began once the vehicle speed stabilized. To ensure comparability across the test results, the vehicle's fuel consumption and carbon emissions are expressed here according to the distance of $100 \mathrm{~km}$ traveled.

\subsubsection{Test Instrument and Vehicle}

The explanatory variable in the field test is velocity and the dependent variable is the vehicle's fuel consumption and carbon emissions. An Ecan analyzer was used to analyze the raw CAN bus data from the passenger car and thus derive the velocity and fuel consumption data. An anemometer monitoring instrument (Xima AS8336, Guangdong, China) was used to measure wind speed. The weather was mild, including stable and relatively slow wind speed. As breezes below $6.0 \mathrm{~m} / \mathrm{s}$ have almost no effect on the movement of ground objects, the wind speed restricted to $6.0 \mathrm{~m} / \mathrm{s}$ and allowed fluctuate within a range of $2.0 \mathrm{~m} / \mathrm{s}$ during the test $[5,25]$. The average measured wind speed was taken as the wind speed value. An AxleLightRLU11 vehicle classification statistical instrument was placed on the test roads prior to the test to select for the passenger car with a large traffic volume. Based on the traffic volume data on the test road and the development prospects of passenger cars, two type of common passenger cars were selected as the dominant vehicle types. One small (Chevrolet Malibu) and one large (Chevrolet Captiva SUV) passenger car were selected for analysis. The Malibu (Vehicle I) is equipped with a four-stroke naturally aspirated gasoline engine, 154 horsepower, $1.5 \mathrm{~L}$ displacement, $1.8 \mathrm{~m}^{2}$ frontal area, and aerodynamic resistance coefficient of 0.35 [23]. The Captiva (Vehicle II) is equipped with a four-stroke naturally aspirated gasoline engine with a power of $167 \mathrm{hp}$, a displacement of $2.4 \mathrm{~L}$, a frontal area of $2.0 \mathrm{~m}^{2}$, and an aerodynamic resistance coefficient of 0.40 [23]. Ten small passenger cars and ten large passenger cars were used for field testing to ensure data reliability. The characteristics of the test vehicles were the same as the dominant vehicle types. The test vehicles were common and economical passenger cars, and they were both supplied with 92\# gasoline [15,29]. In balance gradient field test and fuel consumption field test, every group of data was collected and averaged at least 30 times on the longitudinal slope with the specified gradient.

\subsubsection{Route Selection}

Drivers were required to maintain a cruise speed (from 40 to $120 \mathrm{~km} / \mathrm{h}$ with a mean increase of $10 \mathrm{~km} / \mathrm{h}$ ) throughout the test. According to the road grade and speed limit regulations, the vehicle was required to maintain a cruise speed from $60 \mathrm{~km} / \mathrm{h}$ to $120 \mathrm{~km} / \mathrm{h}$ on the flat straight road sections of Xibao Expressway, and a uniform speed from $40 \mathrm{~km} / \mathrm{h}$ to $60 \mathrm{~km} / \mathrm{h}$ on the flat straight road sections of Provincial Road 306. The grade of Provincial Road 306 is secondary. The length of the flat straight road sections exceeds $1.5 \mathrm{~km}$ and the absolute value of their gradients range from $0.3 \%$ to $0.5 \%$. The test vehicle's fuel consumption was measured on the flat road as it made a round trip; the average value was taken as the fuel consumption of the flat road. Vehicle fuel consumption tests for single and continuous longitudinal slopes were carried out on the Hanzhong to Mianxian first-class road, the Xunyi to Qiupotou second-class road, and the Xianxu Expressway.

The Xibao Expressway and Xianyang-Xunyi Expressway are composed of asphalt pavement in excellent condition with rolling resistance coefficients of 1.25 and wind speeds of $1.0 \mathrm{~m} / \mathrm{s}$. The Hanzhong to Mianxian first-class road is also asphalt pavement but in fair condition, with rolling resistance coefficient of 1.5 and wind speed of $3.0 \mathrm{~m} / \mathrm{s}$. Provincial Road 306 and the Xunyi to Qiupotou second-class 
road are asphalt pavement in poor condition with rolling resistance coefficient of 2.5 and wind speed of $6.0 \mathrm{~m} / \mathrm{s}$.

\subsubsection{Drivers}

Driver performance varies depending on personal driving preferences and experience, so drivers were screened before the field test to ensure they were sufficiently experienced and familiar with the road. Each driver was given 10 days of training and testing to prevent any incorrect driving operations from affecting the test results. The driver was required to maintain a cruise speed normally, avoid any aggressive driving behavior, and maintain a safe distance from the vehicle in front of them. The driving behavior of the test vehicle was not impacted by the other vehicles on the road. Twenty male drivers between 15-20 years of driving experience passed the test. Ten drivers were assigned to drive small passenger cars and the remaining ten to test large passenger cars.

\subsubsection{Other Factors}

Other factors (e.g., traffic flow patterns, pavement condition, emergencies) were controlled throughout the test to prevent undue effects on vehicle carbon emissions. Traffic was in a free-flow pattern throughout the test with no emergencies occurring. The road surface was consistent and free of deformation or damage.

\subsection{Test Results}

Test results were gathered for the flat, single longitudinal slope, and continuous longitudinal slope road sections. The characteristics of the vehicles, fuel quality, and road conditions during field tests were considered in testing the proposed model's ability to predict the carbon emissions of vehicles on test roads. Predicted and measured values were compared to determine the accuracy of the model established and the validate of the carbon emission rules proposed.

\subsubsection{Flat Road}

Different road grades have different speed limit regulations. Vehicle I and vehicle II were required to maintain a cruise speed from $40 \mathrm{~km} / \mathrm{h}$ to $80 \mathrm{~km} / \mathrm{h}$ on the flat straight sections of Provincial Road 306 (Flat Road I) and maintain a cruising speed of $60 \mathrm{~km} / \mathrm{h}$ to $120 \mathrm{~km} / \mathrm{h}$ on the flat straight sections of Xibao Expressway (Flat Road II). Figure 1 shows the vehicle speed and fuel consumption data collected in the field test on the flat road sections. A higher vehicle speed appears to produce greater fuel consumption and higher carbon emissions. The field test data on flat road sections was used for model verification. The maximum relative error values of the predicted and measured fuel consumption values of the two types of test vehicles were $7.89 \%$ and $8.33 \%$, respectively. This indicates that the proposed carbon emission model for the passenger car traversing the flat road is highly accurate and reliable.

\subsubsection{Single Slope Road}

The balance gradients satisfying Vehicles I and II at $60 \mathrm{~km} / \mathrm{h}, 70 \mathrm{~km} / \mathrm{h}$ and $80 \mathrm{~km} / \mathrm{h}$ are $3.6 \%$ and $4.0 \%, 4.0 \%$ and $4.5 \%, 4.5 \%$ and $5.0 \%$, respectively, on the longitudinal slope sections of the Xunyi to Qiupptou secondary road (Road I). The balance gradients are $2.8 \%$ and $3.0 \%, 3.2 \%$ and $3.5 \%$, respectively, for maintaining the cruise speed of $70 \mathrm{~km} / \mathrm{h}$ and $80 \mathrm{~km} / \mathrm{h}$ on the longitudinal slope sections of the Hanzhong to Mianxian Road (Road II). On the longitudinal slopes of the Xianyang-Xunyi Expressway (Road III), the test vehicles were driven at $100 \mathrm{~km} / \mathrm{h}$ and $90 \mathrm{~km} / \mathrm{h}$, respectively, for a balance gradient of 3.5\%. The balance gradients are 3.0\% for Vehicle I and II maintaining cruise speeds of $90 \mathrm{~km} / \mathrm{h}, 80 \mathrm{~km} / \mathrm{h}$, respectively. 


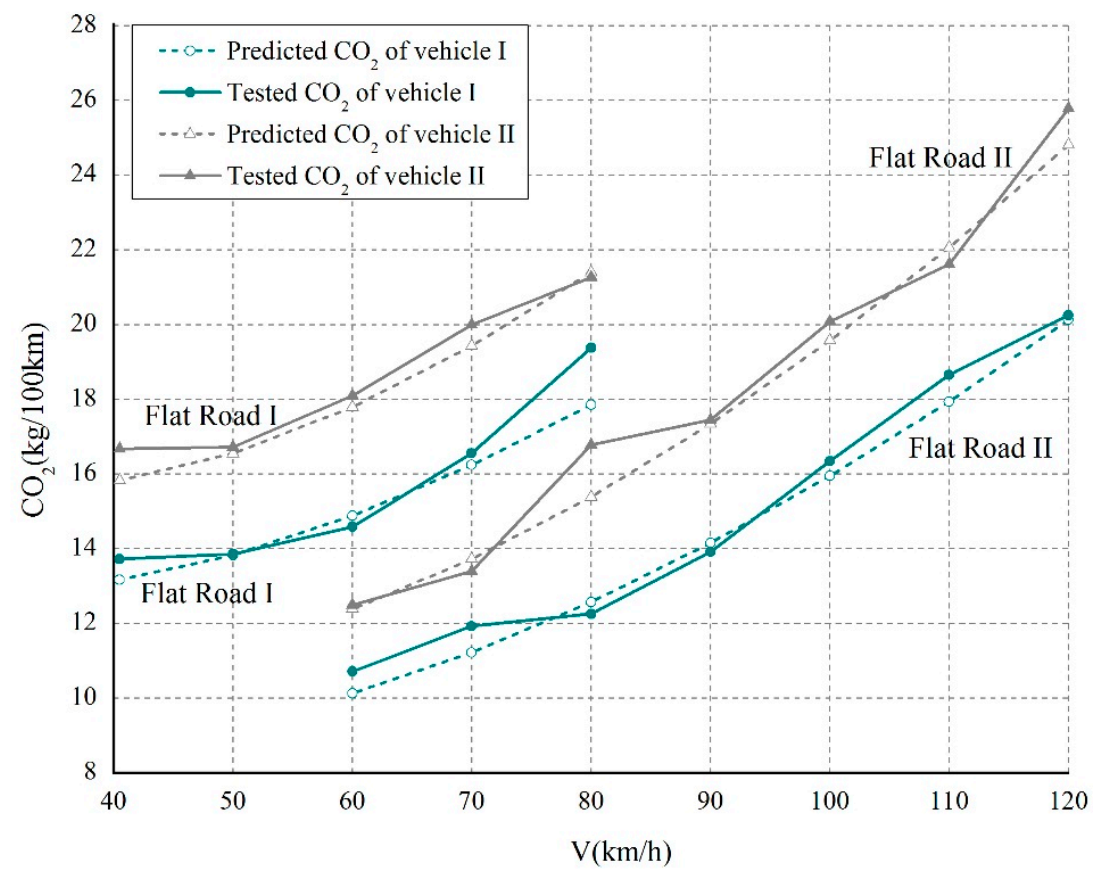

Figure 1. Vehicle $\mathrm{CO}_{2}$ emissions at various speeds on flat road.

The balance gradients of different grades of road were calculated according to Equation (13) as shown in Table 1. The test results are consistent with the calculated balance gradient. The balance gradient from shallow to steep grades versus velocities is basically consistent with the research results of Chang and Morlok [9]. The balance gradient can be used as a boundary condition to explore the differences in carbon emission levels between flat and round-trip longitudinal road sections.

Table 1. Balance gradient of different road grade

\begin{tabular}{cccc}
\hline \multirow{2}{*}{ Road Grade } & \multirow{2}{*}{$(\mathbf{k m} / \mathbf{h})$} & \multicolumn{2}{c}{ Balance Gradient $\mathbf{( \% )}$} \\
\cline { 3 - 4 } & & Vehicle I & Vehicle II \\
\hline & 40 & 2.80 & 2.89 \\
Secondary road & 50 & 3.20 & 3.33 \\
(Road I) & 60 & 3.65 & 3.81 \\
& 70 & 4.14 & 4.34 \\
& 80 & 4.66 & 4.91 \\
First class road & 60 & 2.40 & 2.52 \\
(Road II) & 70 & 2.79 & 2.95 \\
& 80 & 3.23 & 3.43 \\
& 90 & 3.70 & 3.95 \\
& 100 & 4.22 & 4.52 \\
& 60 & 1.97 & 2.07 \\
Expressway & 70 & 2.32 & 2.45 \\
(Road III) & 80 & 2.71 & 2.88 \\
& 90 & 3.15 & 3.36 \\
& 100 & 3.62 & 3.88 \\
& 110 & 4.14 & 4.45 \\
& 120 & 4.70 & 5.07 \\
\hline
\end{tabular}

A round-trip test was run on the single slopes of Road I and Road III as shown in Table 2. Between the predicted and measured carbon emissions on the single slope, the maximum relative errors of Vehicle I and Vehicle II are $9.97 \%$ and $9.33 \%$, respectively. The carbon emission model on the single longitudinal slope thus has a high reliability. 
Table 2. Vehicle carbon emissions on longitudinal slope and flat road.

\begin{tabular}{|c|c|c|c|c|c|c|c|c|c|c|c|c|c|c|c|c|c|c|c|c|}
\hline \multirow{5}{*}{ No. } & \multirow{5}{*}{$\underset{(\mathrm{km} / \mathrm{h})}{\mathrm{V}}$} & \multirow{5}{*}{ I (\%) } & \multicolumn{16}{|c|}{$\mathrm{CO}_{2}$ Emissions $(\mathrm{kg} / 100 \mathrm{~km})$} & \multirow{2}{*}{\multicolumn{2}{|c|}{$\begin{array}{l}\text { Diff. of the offset } \\
\text { Rule (\%) }\end{array}$}} \\
\hline & & & \multicolumn{12}{|c|}{ Longitudinal Slope } & \multicolumn{4}{|c|}{ Flat Road } & & \\
\hline & & & \multicolumn{6}{|c|}{ Vehicle I } & \multicolumn{6}{|c|}{ Vehicle II } & $\begin{array}{l}\text { Vehicle } \\
\text { I }\end{array}$ & $\begin{array}{l}\text { Vehicle } \\
\text { II }\end{array}$ & $\begin{array}{l}\text { Vehicle } \\
\text { I }\end{array}$ & $\begin{array}{l}\text { Vehicle } \\
\text { II }\end{array}$ & \multirow{3}{*}{$\begin{array}{l}\text { Vehicle } \\
\text { I }\end{array}$} & \multirow{3}{*}{$\begin{array}{l}\text { Vehicle } \\
\text { II }\end{array}$} \\
\hline & & & \multicolumn{2}{|c|}{ Predicted $\mathrm{CO}_{2}$} & \multicolumn{2}{|c|}{ Tested $\mathrm{CO}_{2}$} & \multicolumn{2}{|c|}{ Diff. (\%) } & \multicolumn{2}{|c|}{ Predicted $\mathrm{CO}_{2}$} & \multicolumn{2}{|c|}{ Tested $\mathrm{CO}_{2}$} & \multicolumn{2}{|c|}{ Diff. (\%) } & \multirow{2}{*}{\multicolumn{2}{|c|}{ Predicted $\mathrm{CO}_{2}$}} & \multirow{2}{*}{\multicolumn{2}{|c|}{ Tested $\mathrm{CO}_{2}$}} & & \\
\hline & & & Uphill & Downhill & Uphill & Downhill & Uphill & Downhill & Uphill & Downhill & Uphill & Downhill & Uphill & Downhill & & & & & & \\
\hline 1 & 60 & 2.4 & 24.50 & 6.08 & 22.88 & 6.43 & 7.09 & 5.45 & 28.51 & 8.12 & 27.43 & 8.94 & 3.95 & 9.17 & 14.88 & 17.80 & 14.58 & 18.10 & 0.50 & 0.49 \\
\hline 2 & 80 & 1.5 & 19.26 & 5.91 & 19.22 & 5.85 & 0.22 & 0.98 & 22.94 & 7.86 & 24.54 & 7.58 & 6.52 & 3.63 & 12.57 & 15.38 & 12.26 & 16.78 & 2.28 & 4.30 \\
\hline 3 & 80 & 2 & 21.66 & 3.51 & 21.46 & 3.53 & 0.92 & 0.50 & 25.67 & 5.13 & 27.73 & 5.07 & 7.43 & 1.11 & 12.57 & 15.38 & 12.26 & 16.78 & 1.95 & 2.27 \\
\hline 4 & 100 & 1.5 & 22.51 & 9.40 & 21.85 & 9.84 & 3.00 & 4.43 & 26.97 & 12.21 & 25.77 & 13.462 & 4.65 & 9.33 & 15.94 & 19.57 & 16.34 & 20.07 & 3.04 & 2.28 \\
\hline 5 & 100 & 2 & 24.90 & 7.01 & 27.34 & 6.46 & 8.92 & 8.50 & 29.70 & 9.48 & 30.27 & 10.33 & 1.89 & 8.26 & 15.94 & 19.57 & 16.34 & 20.07 & 3.42 & 1.12 \\
\hline 6 & 120 & 1.5 & 26.56 & 13.72 & 28.71 & 14.27 & 7.48 & 3.88 & 32.04 & 17.60 & 33.68 & 18.49 & 4.87 & 4.82 & 20.13 & 24.80 & 20.25 & 25.78 & 6.12 & 1.18 \\
\hline 7 & 120 & 2 & 28.96 & 11.32 & 31.92 & 11.53 & 9.28 & 1.81 & 34.77 & 14.87 & 34.05 & 15.6 & 2.11 & 4.68 & 20.13 & 24.80 & 20.25 & 25.78 & 7.28 & 3.71 \\
\hline 8 & 120 & 3 & 33.75 & 6.53 & 36.95 & 6.88 & 8.66 & 5.07 & 40.23 & 9.41 & 39.29 & 10.18 & 2.38 & 7.54 & 20.13 & 24.80 & 20.25 & 25.78 & 8.22 & 4.06 \\
\hline 9 & 60 & 3.6 & 30.25 & 2.21 & 28.56 & 2.23 & 5.92 & 1.08 & 35.06 & 3.46 & 34.48 & 3.61 & 1.69 & 4.02 & 14.88 & 17.80 & 14.58 & 18.10 & 5.58 & 5.24 \\
\hline 10 & 70 & 4 & 33.14 & 1.98 & 34.02 & 2.18 & 2.58 & 9.06 & 38.40 & 3.66 & 39.7 & 3.48 & 3.28 & 5.24 & 16.24 & 19.43 & 16.55 & 20.00 & 9.34 & 7.95 \\
\hline 11 & 90 & 3 & 27.96 & 1.98 & 26.82 & 2.15 & 9.97 & 7.88 & 33.00 & 3.67 & 34.67 & 3.53 & 4.80 & 3.92 & 14.15 & 17.34 & 13.91 & 17.45 & 4.11 & 9.47 \\
\hline 12 & 100 & 3.5 & 32.09 & 3.19 & 32.64 & 3.25 & 1.70 & 1.92 & 37.88 & 3.56 & 40.27 & 3.65 & 5.93 & 2.45 & 15.94 & 19.57 & 16.34 & 20.07 & 9.81 & 9.39 \\
\hline 13 & 60 & 4 & 32.17 & 2.21 & 29.25 & 2.23 & 9.97 & 1.08 & 37.25 & 2.94 & 36.95 & 2.71 & 0.80 & 8.54 & 14.88 & 17.80 & 14.58 & 18.10 & 7.94 & 9.58 \\
\hline 14 & 70 & 4.5 & 35.54 & 1.89 & 36.92 & 2.08 & 3.74 & 9.09 & 41.13 & 2.52 & 40.12 & 2.38 & 2.51 & 5.93 & 16.24 & 19.43 & 16.55 & 20.00 & 17.80 & 6.25 \\
\hline 15 & 90 & 3.5 & 30.36 & 1.47 & 32.29 & 1.49 & 5.98 & 1.30 & 35.73 & 1.96 & 34.16 & 1.82 & 4.61 & 7.74 & 14.15 & 17.34 & 13.91 & 17.45 & 21.40 & 3.11 \\
\hline 16 & 80 & 3 & 26.45 & 1.65 & 28.96 & 1.67 & 8.67 & 0.93 & 31.13 & 2.21 & 33.82 & 2.25 & 7.96 & 1.96 & 12.57 & 15.38 & 12.26 & 16.78 & 24.96 & 7.47 \\
\hline 17 & 60 & 5 & 36.96 & 2.21 & 38.54 & 2.23 & 4.11 & 1.08 & 42.71 & 2.94 & 40.18 & 3.23 & 6.29 & 8.94 & 14.88 & 17.80 & 14.58 & 18.10 & 39.80 & 19.94 \\
\hline 18 & 50 & 4 & 31.49 & 2.65 & 34.55 & 2.57 & 8.85 & 3.00 & 36.49 & 3.53 & 34.95 & 3.75 & 4.40 & 5.88 & 13.82 & 16.55 & 13.85 & 16.72 & 33.97 & 15.72 \\
\hline 19 & 40 & 4 & 31.21 & 3.31 & 31.55 & 3.4 & 1.06 & 2.68 & 36.25 & 4.41 & 36.79 & 4.55 & 1.48 & 3.03 & 13.17 & 15.83 & 13.72 & 16.68 & 27.36 & 23.94 \\
\hline 20 & 50 & 5 & 36.28 & 2.65 & 38.7 & 2.57 & 6.25 & 3.00 & 41.95 & 3.53 & 39.88 & 3.61 & 5.18 & 2.23 & 13.82 & 16.55 & 13.85 & 16.72 & 48.95 & 30.04 \\
\hline
\end{tabular}


The measured carbon emissions indicate that the main factor affecting the carbon emissions of both vehicles on the round-trip longitudinal slope is speed. A higher speed indeed yields higher carbon emissions, which is consistent with the carbon emission rule on the flat road.

As Vehicles I and II traveled downhill on a gradient close to the balance gradient (Nos. 9-12 and 13-16, respectively), the data shows that the energy consumed by the running resistance is balanced with the gravitational potential energy and no carbon is emitted. Only idling fuel consumption is provided, and the carbon emissions generated are equal to those under idling conditions. When the two types of test vehicles traveled downhill on a gradient less than the balance gradient (Nos. 1-8 and 1-12, respectively), the test drivers needed to slightly step on the gas pedal to maintain the cruise speed, resulting in a small amount of carbon emissions. When the gradient was not greater than the balance gradient, the average vehicle's carbon emissions on the symmetrical slope combination were basically equivalent to the vehicle's carbon emissions on a flat section with equal mileage. Compared to the vehicle's carbon emissions on the flat road, the reduction in carbon emissions on the downhill section of the symmetrical slope combination can offset the increased emissions attributable to the uphill section alone. The tested carbon emission data of vehicles on flat road and on the round-trip longitudinal slope sections in this case are consistent with this rule with a maximum relative error of $9.81 \%$.

As Vehicle I and Vehicle II traversed a longitudinal slope with a gradient greater than the balance gradient (Nos. 13-20 and 17-20 respectively), the energy consumed by aerodynamic resistance and rolling resistance was lower than the gravitational potential energy and the vehicle's speed increased. As the driver stepped on the brake pedal to maintain the cruise speed, the brake drum friction generated heat resulting in a certain amount of energy loss. More propulsive energy is needed on uphill sections with the same gradients as the downhill sections, and a portion of the propulsive energy numerically offsets the energy lost caused by braking on downhill. This results in more carbon emissions during uphill climbing. The field test results of this study support this inference. The balance gradient can be used to determine if energy loss occurs during downhill driving, which is directly related to the low-carbon design of the longitudinal slope section composed with an integral subgrade.

The above conclusions indicate that restricting the road gradient below the balance gradient is conducive to energy savings and $\mathrm{CO}_{2}$ emissions reduction on round-trip longitudinal road sections. Additionally, the results support the fuel consumption rules obtained from field trials conducted by Kanok and Barth [1] that plain routes have better fuel economy than mountainous routes.

\subsubsection{Continuous Longitudinal Slope}

Passenger cars usually travel longitudinal slopes at a uniform speed, and the speed is the average speed of all vehicles on the road $[19,20]$. A continuous longitudinal slope of Road III was selected for subsequent analysis. The average speed on Road III is $100 \mathrm{~km} / \mathrm{h}$ as-measured by the traffic volume survey method. The maximum gradient is $3.5 \%$ and is equal to the measured balance gradient corresponding to the average speed. It shows that the design of this continuous longitudinal slope section meets relevant low-carbon requirements in effect. To clearly observe the various driving behaviors that emerge as a vehicle travels downhill, Vehicle I was required to maintain a cruise speed of $90 \mathrm{~km} / \mathrm{h}$ and its fuel consumption was gathered on the round-trip continuous longitudinal slope. The vertical profile for the continuous longitudinal slope as well as predictions of vehicle propulsion, energy, fuel consumption, and carbon emissions are shown in Figure 2. $\mathrm{R}$ in Figure 2a represents the radius $(\mathrm{m})$ of the vertical curve. The brake energy loss in certain road sections and the equivalent fuel consumption corresponding to the energy loss were calculated according to the proposed model. 


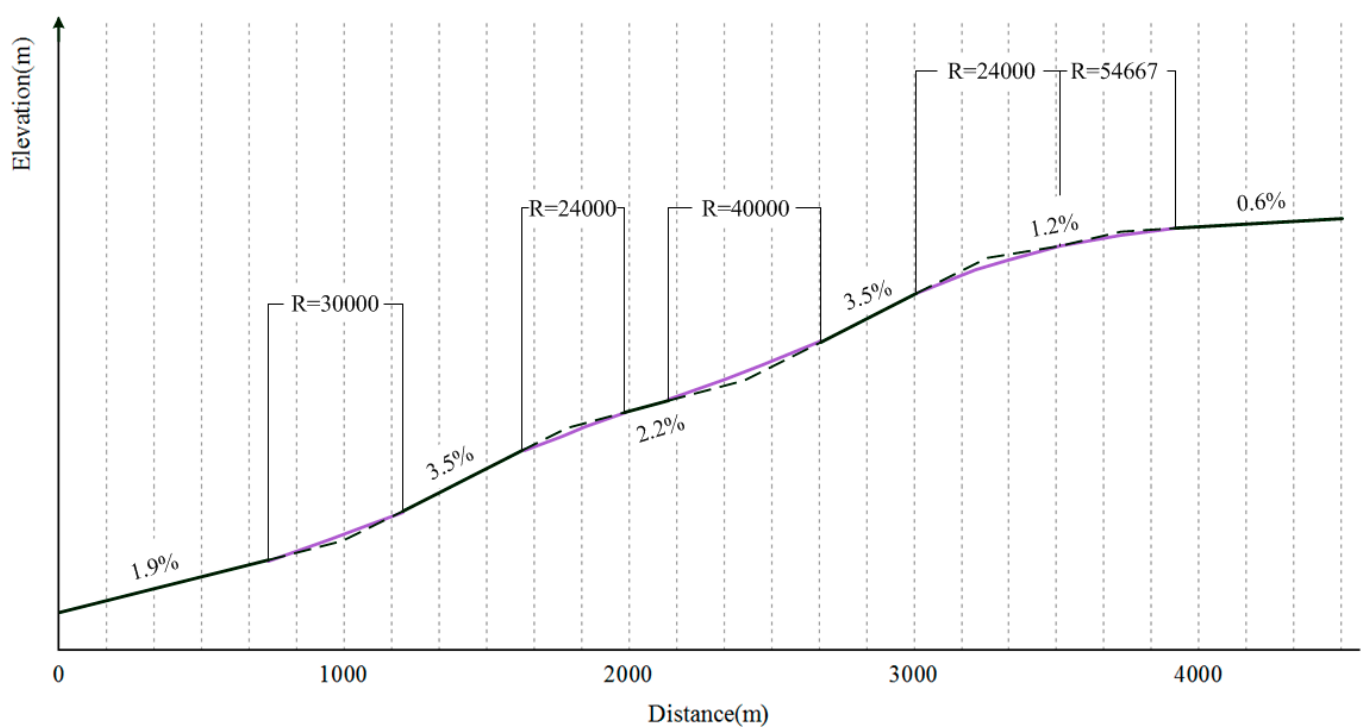

(a)

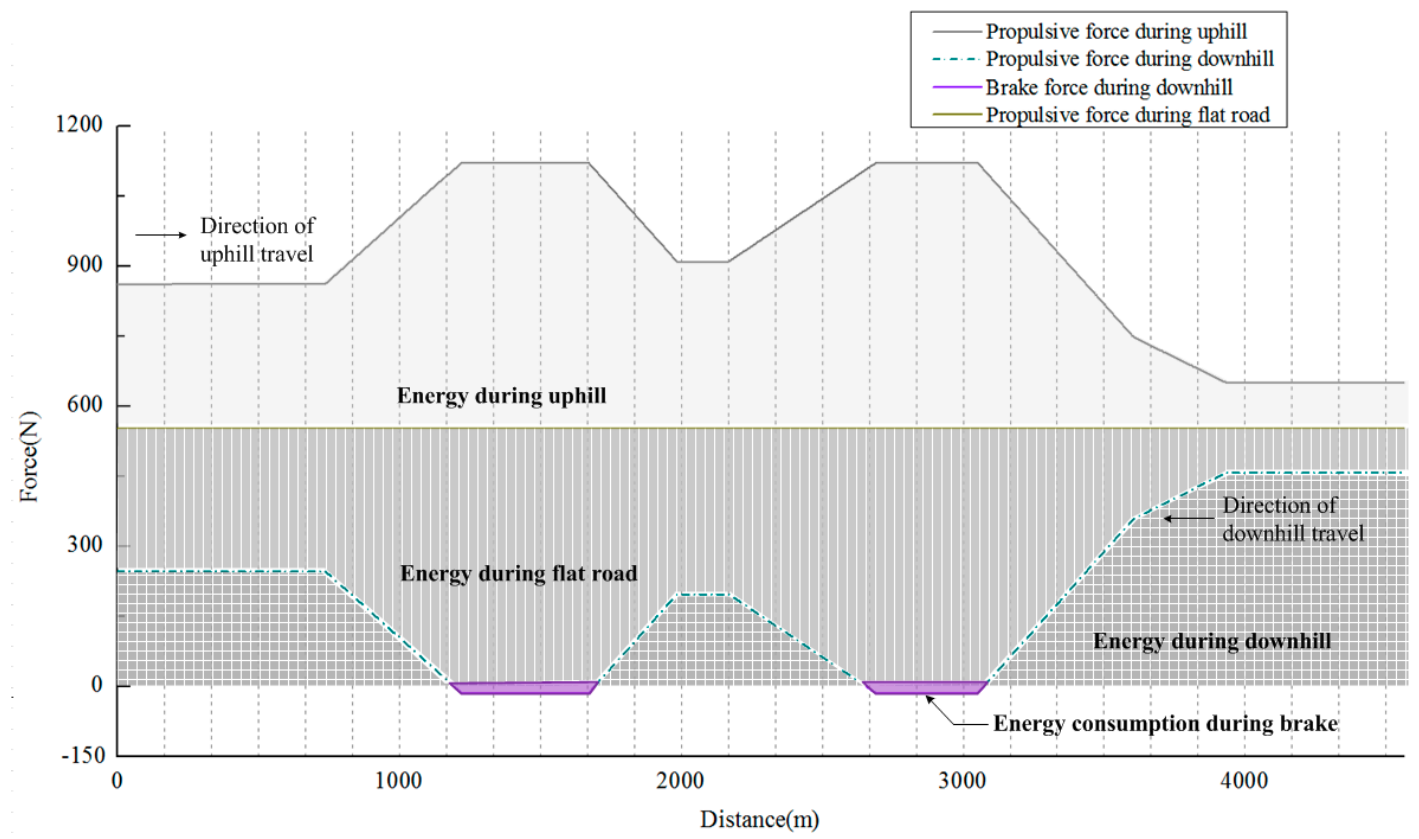

(b)

Figure 2. Cont. 


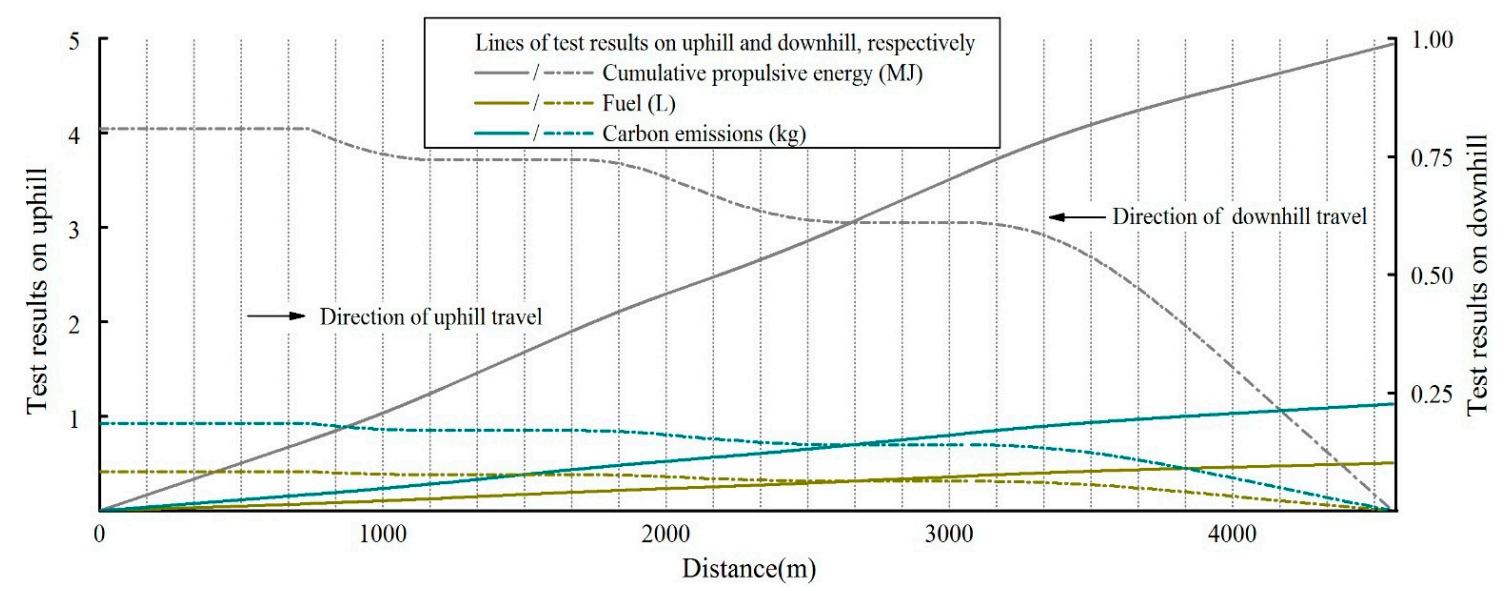

(c)

Figure 2. Evaluation of an example highway in terms of vehicle fuel efficiency, carbon emissions. (a) Vertical profile; (b) force and energy profile; (c) cumulative propulsive energy, fuel consumption and carbon emissions profile.

The measured vehicle's carbon emissions on the uphill and downhill road sections is $28.17 \mathrm{~kg} / 100 \mathrm{~km}$ and $6.03 \mathrm{~kg} / 100 \mathrm{~km}$, respectively. The gradient of certain longitudinal slope sections in the continuous road do exceed the balance gradient. Using the proposed carbon emission model, the predicted carbon emissions on continuous uphill and continuous downhill sections are $25.81 \mathrm{~kg} / 100 \mathrm{~km}$ and $5.80 \mathrm{~kg} / 100 \mathrm{~km}$, respectively. The converted $\mathrm{CO}_{2}$ emission rate and cumulative $\mathrm{CO}_{2}$ emissions corresponding to the brake energy loss of the vehicle on the downhill sections with gradients larger than the balance gradient are $3.86 \mathrm{~kg} / 100 \mathrm{~km}$, and $31.58 \mathrm{~kg}$, respectively. The relative errors of the predicted and measured values of uphill and downhill sections are $8.38 \%$ and $3.81 \%$, respectively, which implies that the proposed model of vehicle carbon emissions on continuous longitudinal slopes is accurate. The average gradient of the continuous longitudinal slope is $2.258 \%$. Using the proposed carbon emission model, the predicted carbon emissions on uphill and downhill sections with the average gradient are $25.81 \mathrm{~kg} / 100 \mathrm{~km}$ and $3.96 \mathrm{~kg} / 100 \mathrm{~km}$, respectively. These above results suggest that $\mathrm{CO}_{2}$ emissions on the continuous uphill section is equal to that on the uphill section with the average gradient and equal mileage. Vehicle braking generates energy loss when the gradient of certain longitudinal slopes in a continuous downhill section is greater than the balance gradient. The gradients of part of the slope in the continuous downhill section are greater than the balance gradient. The carbon emission rate on these sections is the idling carbon emission rate and is not negative. For a fixed height difference, the other longitudinal slope sections have a smaller gradient and a higher carbon emission rate, which leads to an increase in cumulative carbon emissions on the continuous downhill section. It implies that there would be no difference in $\mathrm{CO}_{2}$ emissions among different routes with different road grade profiles within the gradient range that is not greater than the balance gradient.

The main indicator affecting vehicle carbon emissions on the one-way continuous longitudinal slope is the average gradient. Vehicle carbon emissions are independent of single longitudinal slope and vertical curve designs. This conclusion applies to cases where all gradients of the downhill in the continuous longitudinal slope are not greater than the balance gradient. On the uphill section, the main cause of carbon emissions is the elevation difference; its carbon emission rate is equal to that on the longitudinal slope with an average gradient corresponding to the elevation difference. If there are no road sections of continuous downhill road with a gradient greater than the balance gradient, the carbon emissions of the vehicle traveling downhill is equal to that on the downhill with the average gradient and equal mileage. When the average gradient of the continuous downhill section is greater than the balance gradient, there must be certain slope sections with a gradient greater than the balance gradient. Even if the average gradient of the continuous downhill slope is less than the balance gradient, there 
may be certain slope sections with gradients greater than the balance gradient. In a slope section with gradient exceeding the balance gradient, vehicle braking can produce energy loss when traveling downhill. The difference in propulsive energy between the round-trip continuous longitudinal slope and the flat road with equal mileage is equal to the energy loss of the vehicle braking as it travels downhill. The shaded area in Figure $2 b$ illustrates this rule.

The fuel consumption of the vehicle on the round-trip continuous longitudinal slope is not less than the vehicle's fuel consumption on a flat road with equal mileage. The difference in fuel consumption between them is equal to the fuel consumption corresponding to the energy loss of the vehicle braking as it travels downhill. There is no energy loss when all gradients on the continuous longitudinal slope are below the balance gradient. In this case, the vehicle has the lowest carbon emissions on the round-trip continuous longitudinal slope, which is equivalent to the carbon emissions on a flat straight road with equal mileage.

The propulsive energy, fuel consumption, and carbon emissions of the vehicle are proportional to each other. The specific proportional relationship can be observed in the proposed model and is shown in Figure 2c. The rules of propulsive energy, fuel consumption, and carbon emissions of the vehicle are consistent.

\section{Discussion}

A theoretical carbon emission model for passenger cars traveling at cruising speed on uphill, downhill, and flat roads was established in this study based on the law of conservation of mechanical energy, the first law of thermodynamics and the vehicle longitudinal dynamics theory. The impact of highway longitudinal profile design indicators on the vehicle's carbon emissions was also revealed. Other findings can be summarized as follows.

1. When all gradients of the downhill in the continuous longitudinal slope are below the balance gradient, for a fixed height difference, the vehicle carbon emissions are equal to those on the slope with an average gradient and equal mileage regardless of the design features of the vertical profile. There would be no difference in $\mathrm{CO}_{2}$ emissions among different routes with different road grade profiles within the balance gradient range.

2. When the average gradient of the continuous longitudinal slope is greater than the balance gradient, the gradient of certain longitudinal slope sections must be greater than the balance gradient. Braking during downhill travel on these slope sections causes energy loss. Excess carbon emissions are produced on the uphill direction on these slope sections compared to the slope with a balance gradient. The gradient should be kept below the balance gradient to reduce this unnecessary energy loss on downhill and excess carbon emissions on uphill. When the gradient of the longitudinal slope composed with an integral subgrade is larger than the balance gradient, a longer slope length results in greater cumulative carbon emissions; this is not conducive to energy savings or carbon emission abatement.

3. Under the same driving conditions (e.g., driving speed, road conditions, vehicle types, road environment, traffic flow conditions), driving downhill is generally more fuel-efficient than driving uphill. This perception is correct for a one-way trip longitudinal slope. For a round-trip longitudinal slope, however, the actual fuel efficiency is more complex. According to the law of conservation of mechanical energy, the first law of thermodynamics, the vehicle longitudinal dynamics theory, and results presented in this paper, when all the gradients of the longitudinal slope sections are not greater than the balance gradient, the carbon emissions of the vehicle on the round-trip longitudinal slope are equal to those on a flat road. When there is a gradient of the single slope section in the continuous longitudinal slope which exceeds the balance gradient, the energy loss caused by the vehicle braking as it travels downhill direction on the slope section is equal to the propulsive energy increment during the uphill direction travel on the slope section and during the flat road with equal mileage as round-trip longitudinal slope. It is not conducive to energy-saving or emission-reduction in regard to the two-way traffic on the longitudinal slope. 
4. The road gradient should be kept below balance gradient in the vertical profile design to save energy and minimize $\mathrm{CO}_{2}$ emissions from two-way traffic. In a low-carbon design tailored to the longitudinal slope, considering the balance gradient, the carbon emissions of vehicles on the two-way longitudinal slope section is approximately the same as that on an equal-mileage flat road. Controlling all gradient of the longitudinal slope can achieve fuel economy and low carbon performance of vehicles traveling at cruising speed on round trip continuous longitudinal slope sections.

This study centers on the carbon emission rules of passenger cars on longitudinal slopes. The carbon emission model in this paper was established in accordance with the real-world driving conditions. The vehicles were required to maintain a uniform operating speed in the field test. The vehicle speed was idealized and regarded as a uniform speed to prevent carbon emissions from suffering interference from vehicle speed fluctuations. The proposed model thus has limited ability to forecast the carbon emissions of vehicles that fluctuate in speed during travel. This factor should be considered in future studies to more accurately estimate real-world driving conditions. Additionally, only two common passenger cars were selected as typical vehicle types for testing, so the model proposed above may not reflect the carbon emissions of other vehicles and do merit consideration as such. In the future, the proposed models may be modified to account for specific parameters (e.g., vehicle type, engine type, fuel type, vehicle load, frontal area, tire type) for application to other vehicle categories. Further, the mechanical efficiency and fuel utilization rate discussed in this paper are idealized for specific gasoline engine and current gasoline fuel characteristics. Other vehicle categories and other fuel-powered vehicles should be taken into consideration. The default values of mechanical efficiency and fuel utilization rate are fixed. These assumptions may have affected the outcomes of the tests presented in this paper.

Author Contributions: Methodology, Y.D., J.X. and M.Y.; validation, Y.D. and J.X.; formal analysis, Y.D., J.X. and M.Y.; investigation, Y.D. and J.X.; data curation, Y.D. and J.X.; writing—original draft preparation, Y.D.; writing - review and editing, Y.D.; visualization, J.X.; supervision, J.X.; project administration, J.X.; funding acquisition, J.X. All authors have read and agreed to the published version of the manuscript.

Funding: This research was funded by the National Key Research and Development Program of China (Grant no. 2016YFC0802208).

Acknowledgments: The opportunity to research this topic is made possible by funding provided by Department of Transportation of Shaanxi Province. Meanwhile, we thank the drivers for their cooperation during the field experiment.

Conflicts of Interest: The authors declare no conflict of interest.

\section{References}

1. Boriboonsomsin, K.; Barth, M. Impacts of road grade on fuel consumption and carbon dioxide emissions evidenced by use of advanced navigation systems. J. Transp. Res. Board 2009, 2139, 21-30. [CrossRef]

2. Park, S.; Rakha, H. Energy and environmental impacts of roadway grades. Transp. Res. Rec. 2006, 1987, 148-160. [CrossRef]

3. Demir, E.; Bektas, T.; Laporte, G. A comparative analysis of several vehicle emission models for road freight transportation. Transp. Res. D Transp. Environ. 2011, 6, 347-357. [CrossRef]

4. Crolla, D.; Mashadi, B. Vehicle Powertrain Systems; Wiley John Wiley\& Sons, Ltd.: New York, NY, USA, 2012.

5. Gillespie, T.D. Fundamentals of Vehicle Dynamics; Society of Automotive Engineers, Inc.: Tokyo, Japan, 1992.

6. Dreier, D.; Silveira, S.; Khatiwada, D. The influence of passenger load, driving cycle, fuel price and different types of buses on the cost of transport service in the BRT system in Curitiba, Brazil. Transportation 2018, 46, 2195-2242. [CrossRef]

7. Dreier, D.; Silveira, S.; Khatiwada, D. Well-to-Wheel analysis of fossil energy use and greenhouse gas emissions for conventional, hybrid-electric and plug-in hybrid-electric city buses in the BRT system in Curitiba, Brazil. Transp. Res. D Transp. Environ. 2017, 58, 122-138. [CrossRef] 
8. Kang, M.; Shariat, S.; Jha, M.K. New highway geometric design methods for minimizing vehicular fuel consumption and improving safety. Transp. Res. C Emerg. Technol. 2013, 31, 99-111. [CrossRef]

9. Chang, D.; Morlok, E. Vehicle speed profiles to minimize work and fuel consumption. J. Transp. Eng. 2005, 131, 173-182. [CrossRef]

10. Ehsani, M.; Ahmadi, A.; Fadai, D. Modeling of vehicle fuel consumption and carbon dioxide emission in road transport. Renew. Sustain. Energy Rev. 2016, 53, 1638-1648. [CrossRef]

11. Barth, M.; Younglove, T.; Scora, G. Development of a heavy-duty diesel modal emissions and fuel consumption model. In California Partners for Advanced Transit and Highways (PATH); Technical Report; UC Berkeley: Berkeley, CA, USA, 2005.

12. Scora, G.; Barth, M. Comprehensive Modal Emission Model (CMEM), Version 3.01: User's Guide; Technical Report; University of California: Oakland, CA, USA, 2006.

13. Barth, M.; An, F.; Younglove, T.; Scora, G.; Levine, C.; Ross, M.; Wenzel, T. Development of a Comprehensive Modal Emissions Model. NCHRP Web Only Doc. 2000, 122, 11-25.

14. Abou-Senna, H.; Radwan, E.; Westerlund, K. Using a traffic simulation model (VISSIM) with an emissions model (MOVES) to predict emissions from vehicles on a limited-access highway. J. Air Waste Manag. Assoc. 2013, 63, 819-831. [CrossRef] [PubMed]

15. Dong, Y.P.; Xu, J.; Liu, X.; Gao, C.; Ru, H.; Duan, Z. Carbon Emissions and Expressway Traffic Flow Patterns in China. Sustainability 2019, 11, 2824. [CrossRef]

16. Dong, Y.P.; Xu, J.; Li, M.; Jia, X.; Sun, C. Association of Carbon Emissions and Circular Curve in Northwestern China. Sustainability 2019, 11, 1156. [CrossRef]

17. Ko, M.; Lord, D.; Zietsman, J. Environmentally Conscious Highway Design for Vertical Grades. Transp. Res. Rec. J. Transp. Res. Board 2012, 2341, 53-65. [CrossRef]

18. Lan, C.J.; Menendez, M. Truck Speed Profile Models for Critical Length of Grade. J. Transp. Eng. 2003, 129, 408-419. [CrossRef]

19. AASHTOA. Policy on Geometric Design of Highways and Streets; American Association of State Highway and Transportation Officials: Washington, DC, USA, 2011.

20. Japan Road Association. Explanation and Application of Road Structure Ordinance; Maruzen Publishing Co., Ltd: Tokyo, Japan, 2004.

21. Technical Standards for Highway Engineering (JTG B01-2014); China Standard Press: Beijing, China, 2014.

22. Yan, M.H.; Xu, J.L. Prediction Model for Brake-Drum Temperature of Large Trucks on Consecutive Mountain Downgrade Routes Based on Energy Conservation Law. Math. Probl. Eng. 2018, 2018, 1-10. [CrossRef]

23. Wong, J.Y. Theory of Ground Vehicles, 4th ed.; John Wiley\& Sons, Ltd.: New York, NY, USA, 2008.

24. Rakha, H.; Lucic, I.; Demarchi, S.H.; Setti, J.R.; Aerde, M.V. Vehicle Dynamics Model for Predicting Maximum Truck Acceleration Levels. J. Transp. Eng. 2001, 127, 418-425. [CrossRef]

25. Hucho, W.; Sovran, G. Aerodynamics of Road Vehicles. Annu. Rev. Fluid Mech. 1993, 25, 485-537. [CrossRef]

26. Ministry of Communications of the People's Republic of China. Design Specification for Highway Alignment (JTG B01-2017); China Standard Press: Beijing, China, 2017.

27. Ministry of Ecology and Environment the People's Republic of China. Limits and Measurement Methods for Emissions from Light-Duty Vehicles (GB 18352.5-2013); China Environmental Science Press: Beijing, China, 2018.

28. Ministry of Energy of the People's Republic of China. Gasoline for Motor Vehicles (GB 17930-2016); China Standard Press: Beijing, China, 2016.

29. National Development and Reform Commission; Department of Climate Change. Land Transport Companies' Greenhouse Gas Emissions Accounting Methods and Reporting Guidelines (Trial); NDRC: Beijing, China, 2015.

30. Ruzzenenti, F.; Basosi, R. Evaluation of the energy efficiency evolution in the European road freight transport sector. Energy Policy 2009, 37, 4079-4085. [CrossRef]

31. IPCC (Intergovernmental Panel on Climate Change). Guidelines for National Greenhouse Gas Inventories. In Prepared by the National Greenhouse Gas Inventories Program; Egglestone, H.S., Buendia, L., Miwa, K., Ngara, T., Tanabe, K., Eds.; IGES: Tsukuba, Japan, 2006. 
32. National Development and Reform Commission. Climate Change Division. Second National Communications on Climate Change in the People's Republic of China; China Economic Publishing House: Beijing, China, 2013.

33. Chinese Government. The First Two-Year Update Report on Climate Change in the People's Republic of China. Available online: http://qhs.mee.gov.cn/kzwsqtpf/201907/P020190701765971866571.pdf (accessed on 13 November 2019). 